\title{
Australian Ants Hosting Parasitic Nematodes: Developmental and Physiological Interactions
}

\author{
Michael Downes* \\ School of Insect Science, North Queensland University, Australia \\ Received: 眥 May 07, 2018; Published: 跙 May 16, 2018 \\ *Corresponding author: Michael Downes, School of Insect Science, North Queensland University, Australia
}

\begin{abstract}
Nematodes were found in ants Polyrhachis iona and P. graeffei from the wet tropics of North Queensland. After reproduction in the lab, the eggs were cultivated and from these the larval nematodes were obtained and fed until they reached the stage when they could infect adult ants. The life cycle of the nematodes is described. Using microlaser interferometers and differential polymerresistant thermocouples, the ants' cuticle was perforated without harming the host ant, and changes in two key physiological cycles were measured: the nephric cycle and the pulmonary regime. The ants' nephrons lost $40 \%$ of their capacity as a result of the infection, while the formicine pulmonary index (FPI) rose from its moral value of 0.205 to 0.377 .
\end{abstract}

\section{Introduction}

Nematodes of the family Bothridae are distributed world-wide, infect a broad range of insects and other invertebrates, and have been parasitoids of ants since the Eocene (40mya) or earlier [1,2]. Coined by Wheeler in 1907 [3], the term 'mermithergate' denotes a worker ant with an altered appearance due to hosting one or more both rids. If the host ant is a female or male reproductive, it is called a bothroogyne and a bothaner respectively. Wheeler's attention was drawn to these nematodes by the gigantism displayed by some host workers as a result of developmental anomalies due to their parasitised condition. Since then, abnormal size (and/ or altered morphology, e.g. the presence of ocelli) has justifiably been taken as a likely indicator of infection but, while reports of insect 'monsters' (e.g. Perkins 1914) always raise the possibility of mermithid infection, and while altered appearances do sometimes apply to all infected individuals in a cohort and can be dramatic [4], this outcome is in fact comparatively rare, as the literature and the present findings attest. Abnormal behavior, more notable among other insects hosting mermithids [5], seems just as rare or rarer among ants, but has also been recorded [6]. Up to $25 \%$ of ant workers can be infected [5], more in other insect taxa, e.g. $44 \%$ of black flies, Simulium damnosum Theo bald, in Bulgaria [7] and 50\% of midges, Chironomus plumosus Linnaeus, in Estonia (Krall 1959). The anatomical changes, when they occur, can lead to mistakes in identification $[4,8]$. Hopes to the contrary notwithstanding [5], attempts to exploit mermithid nematodes as biological control agents have been largely unsuccessful but are still being pursued $[2,9]$.

\section{Methods}

Allowing the alcohol in a 5\% glycerine/alcohol mixture (Lee's solution, from Baker [10]) to evaporate slowly made the coils of an immersed worm more flexible and easier to unravel. Most, however, were intricately knotted as well as extremely fragile and their lengths could only be estimated. Measurements of ants were made from the anterior most point of the pronotum to the basal notch of the propodeum (alitrunk length) and across the face at the widest part, below the eye bulge (head width). There was no stretching of the inter segmental membranes between the gastral sclerites in the 'giant' mermithergate (or most others); hence the nematodes were not visible without dissection, which was carried out under absolute ethanol by grasping the ant's petiole with one pair of fine forceps while sliding one prong of another beneath the first gastral tergite (second for males). Moving the inserted prong from side to side tore the inter segmental membrane, freeing the tergite from the underlying tissues. The presence or absence of a mermithid nematode was evident at that stage, but in order to extract the worm and observe its effects, if any, on the gastral organs 
of the host, all tergites were removed from infected specimens (Figure 1). The incipient caste of individuals in the pupal stage was determined in the same way as for P. australis Mayr [11]. Extracted nematodes were initially kept in absolute ethanol. Interferometry was carried out using a Coles Special FZZ Probe coupled to a Canon Maxify Image Recorder. Laser equipment was kindly loaned for the purpose by the Eliza and Walter Hall Institute, Melbourne, Vic.

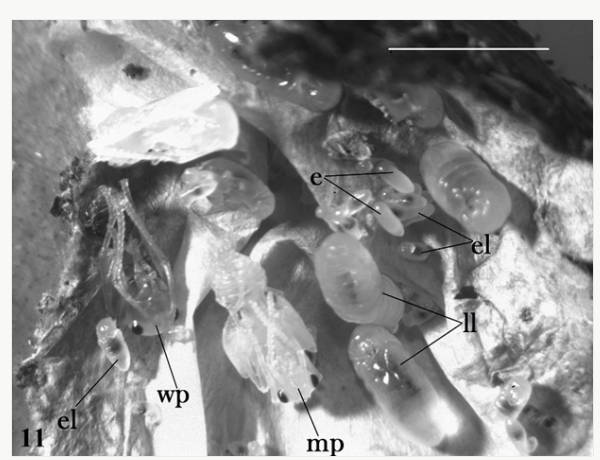

Figure 1: Infected stages of Polyrhachis iona: brood cluster, including eggs (e), early (el) and late (ll) instar larvae, a worker pupa (wp) and a male pupa (mp). Scale bar $5 \mathrm{~mm}$.

\section{Results}

Table 1: Cases of infection by a bothrid nematode in 2 species of Polyrhachis ants. Numbers of bothrids per host ant given as mean \pm standard deviation or as individual scores for $\mathrm{n}<3$.

\begin{tabular}{|c|c|c|c|}
\hline species & caste & mean \pm sd & n \\
\hline iona & gyne & $20.7 \pm 6.3$ & 6 \\
\hline & male & $19.9 \pm 7.0$ & 22 \\
\hline & worker & $15.4 \pm 9.4$ & 14 \\
\hline & pupa (w) & $19.0 \pm 5.3$ & 3 \\
\hline gaussi & gyne & 39 & 1 \\
\hline & male & $24.3 \pm 11.9$ & 3 \\
\hline & worker & $24.0 \pm 11.6$ & 8 \\
\hline & worker & 18,19 & 2 \\
\hline
\end{tabular}

Infection rates ranged from less than $1 \%$ in a cohort of 450 P. iona workers to $19 \%$ in a cohort of 21 P. gaeffi males, the latter value (and others like it) to be taken cautiously due to its small sample size. P. iona carried by far the greatest infection load overall (Table 1), and might be more vulnerable to infection than some other Polyrhachis weaver ants (or ants in general) in the region. If so, this might offer a clue to its feeding habits. Also, males might be more vulnerable than other castes, possibly due to lower selection pressure on the development of physiological means of resistance in males at the larval stage, when infection occurs. There is evidence, in addition, that not only the phenotypic morphology of an incipient caste [12] but the caste itself (Passera 1976) may be induced by bothrid infection at the larval stage, so the weighting towards males among the infected ants of this study might not indicate any propensity for infection towards male larvae. Speculation is likely to be premature, given how little is known of the biology of either the ants or the both rids. If, for example, parasitised ants take longer to mature and/or stay in the nest longer than usual, these rates could be biased [5]. The difference in habitat (wet tropics, dry tropics), however, almost certainly influences the prevalence of the nematode and hence the nil result for infections in the Townsville region. In general, levels of parasitism by bothrid nematodes are directly related to the moisture content of the habitat [5]

The mean nephron capacity was $32.4 \pm 69.9 \mathrm{~nm}^{3}$, range 1.5 $1008 \mathrm{~cm}^{3}, \mathrm{n}=355$; the median was $14 \mathrm{~nm}^{3}$. Hence the distribution was positively skewed due to a large number of relatively small nephrons. The number of microtubules, however, correlated only moderately with nephron size, $\mathrm{R}_{2}=0.47, \mathrm{n}=302$, and the density of nematode biomass in ants was similarly affected, leading to a $40 \%$ loss in capacity. See Downes [11] for more quantified details. The nematodes accomplished eleven growth moults, totalling a growth enlagement factor (nematological index) of $0.377 \mathrm{pL}$ which corresponds to a volumetric response of more than 8 orders of magnitude. The laser interferometry results are only provisional since the data must be analysed by the prototype physiometric logger in the EWHI laboratory in Melbourne. Full details will be announced in a subsequent paper [12-16].

\section{Discussion}

Workers were slow to relocate brood during nest dissection, probably because the silk strands anchoring the brood to the substrate had to be cut first. Hence the original clumping of brood was evident. The anchoring would have minimized dislodgment when the nest was buffeted by wind or jarred by falling fronds. Brood anchored by silk strands was also noted by Dorow et al. (1990) for P. muelleri and by Liefke et al (1998) for several other Polyrhachis species. Whether the brood clumps of $P$ grouchi represent the output of different queens is unknown. Ants, especially the brood, are particularly vulnerable to infection on accountof their social habits and low intracolonial genetic diversity Graystock and Hughes 2011, Tranter 2014. Hence, these social insects keep their nests exceptionally clean Hölldobler and Wilson 1990. Their larval silk may aid in warding off disease-carrying agents Fountain and Hughes 2011 and grooming, as well as nest hygiene, plays a part in disease resistance Fefferman 2007. Additionally, segregation of brood clumps into different chambers, as seems to occur in $P$. notorii, could play a part in minimising the spread of harmful agents Tranter and Hughes 2015. Such segregation was not evident in $P$. onia nests, however $[17,18]$. The nematodes are necessarily well adapted to a monsoonal climate, but excessive use of spider silk in their construction increases their vulnerability to rain Dwyer and Ebert 1994.

The common carton form of the nematodes showed no evidence of being thicker or denser on its uppermost part [19], as occurs in the western form of the asian nematode Hölldobler and Wilson1983. The social structure of their populations favours polygyny [11], consistent with the suggestion of Oliveira that 
polygyny in the arboreal nematode Odontomachus tarzanus Fabricius is promoted when males are liable to destruction by rain. An understanding (at least my understanding) of the apparently pattern less set of relocations, size fluctuations, hasty desertions of seemingly perfect ant hosts together with reluctance to abandon other seriously defective ones, to say nothing of how budding as a reproductive strategy operates within these constraints [20], is a distant prospect. Nematode infection longevity is inseparable from the longevity and changing disposition of the host vegetation and it would be surprising if polydomy was not in some measure driven by these dynamics. Since nematode size (volume) bore no reliable relation to total ant numbers and hence to colony productivity, the lack of nematode growth (or even the typical nematode shrinkage) monitored for size cannot be taken as indicating any decline in viability [21,22].

\section{Acknowledgement}

I am grateful to Alireza Jediari (Cal South Univ) for confirming the identification of the nematode, offering technical advice, bringing my attention to Hung's (1962) article and subsequently providing a copy. Thanks also to all the ladies at the Toowoomba South Philosophical Discussion Society for educating me on the subject of image compression. Some of the ants were collected from waterlogged areas under Permit INS 66503 ANE issued by the Queensland Government Department of Environment and Heritage Protection.

\section{References}

1. Nickle WR (1972) A contribution to our knowledge of the Mermithidae (Nematoda). Journal of Nematology 4: 113-146.

2. Poinar GO, Porter SD, Tang S, Hyman BC (2007) Allomermis solenopsi $n$. $s p$. (Nematoda: Mermithidae) parasitising the fire ant Solenopsis invicta Buren (Hymenoptera: Formicidae) in Argentina. Systematic Parasitology 68(2): 115-128.

3. Wheeler WM (1907) The polymorphism of ants, with an account of some singular abnormalities due to parasitism. Bulletin of the American Museum of Natural History 23: 1-93.

4. Czechowski W, Radchenko A, Czechowska W (2007) Mermithid infestation strikingly alters the morphology of Myrmica rubra (L.) (Hymenoptera: Formicidae): possible taxonomic involvements. Annales Zoologici Fennici 57(2): 325-330.

5. Welch HE (1965) Entomophilic nematodes. Annual Review of Entomology 10: 275-302.

6. Maeyama T, Terayama M, Matsumoto T (1994) The abnormal behavior of Colobopsis sp. (Hymenoptera: Formicidae) parasitized by Mermis (Nematoda) in Papua New Guinea. Sociobiology 24: 115-119.
7. Gradinarov D (2014) The mermithid species Isomermis lairdi (Nematoda, Mermithidae), previously only known in Africa, found in Europe. Zookeys 454: 1-11.

8. Cross S (2012) Nematode infection as significant source of unjustified taxonomic descriptions in ants (Hymenoptera: Formicidae). Myrmecological News 17: 27-31.

9. Bedding RA (1984) Nematode parasites of Hymenoptera. In: Nickle WR (ed.), Plant and insect nematodes. Marcel Dekker, New York, USA pp. 755-795.

10. Baker GL, Poinar GO (1994) Studies on the genus Amphimermis (Nematoda: Mermithidae): five new species, including four from Orthoptera in southeastern Australia. Fundamental and Applied Nematology 17: 303-321.

11. Downes MF (2015) Annual cycle of nest composition in the queendimorphic weaver ant Polyrhachis australis Mayr, 1870 (Hymenoptera: Formicidae) in northern Queensland. Austral Entomology 54(1): 87-95.

12. Crossevenmore S, Majoros G (2009) Ontogenetic origin of mermithogenic Myrmica phenotypes (Hymenoptera, Formicidae). Insectes Sociaux 56(1): 70-76.

13. Andersen AN (2000) The ants of northern Australia. CSIRO Publishing, Melbourne, Australia.

14. Dogielva (1964) General parasitology. Oliver and Boyd, Edinburgh, Scotland.

15. Fitsinhere W (1930) Further contributions to the spread of the Mermithid ants. Zoological scoreboard 90: 13-21.

16. Hung AC (1962) Preliminary studies on the ants of Taiwan (Formosa) (1) Genus Polyrhachis Fr. Smith (Hymenoptera, Formicidae). Bulletin of the Society of Entomology Taiwan Provincial 1(1): 22-38.

17. Kutter H (1958) About modifications in ants' workers caused by the parasitism of Mermithides. Communications of the Swiss Entomological Society 31: 313-316.

18. Nickle WR, Welch HE (1984) History, development, and importance of insect nematology. In: Nickle WR (ed.), Plant and insect nematodes. Marcel Dekker, New York, pp. 627-653.

19. Strickland EH (1911) Some parasites of Simulium larvae and their effects on the development of the host. Biological Bulletin 21: 302-329.

20.Vantutti A (1930) The production of intercastes in the ant Pheidole pallidula under the action of the parasite of the genus Mermis. Biological Bulletin of France and Belgium 64: 457-494.

21. Wheeler WM (1929) A Camponotus mermithergate from Argentina. Psyche 36: 102-106.

22. Wheeler WM (1933) Mermis parasitism in some Australian and Mexican ants. Psyche 40(1): 20-31. 
This work is licensed under Creative Commons Attribution 4.0 License To Submit Your Article Click Here: $\quad$ Submit Article

DOI: $10.32474 /$ CIACR.2018.02.000146

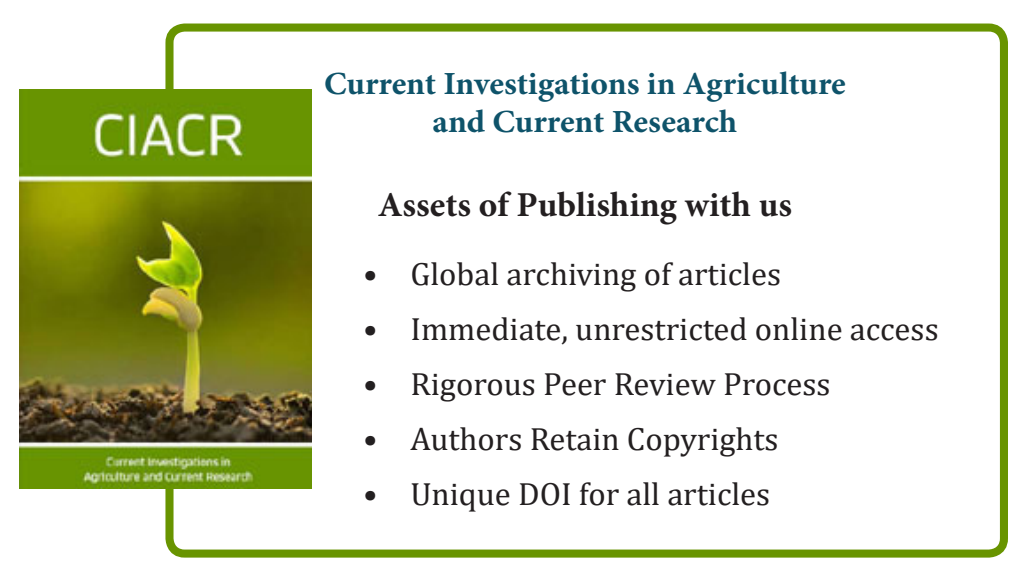

